\title{
Contribution of worker participation to increase the efficiency of firms
}

\author{
P. de Villiers* and G. Kooy \\ Department of Economics, University of Stellenbosch \\ Stellenbosch 7600, Republic of South Africa \\ apdv@sun.ac.za
}

Received January 2004

\begin{abstract}
There are many factors that may lead to inefficiencies in a firm. One reason is the existence of a principal-agent problem. Linked with this problem is asymmetric information, unaligned motives of principals and agents, distrust (that was rampant in the era of apartheid in South Africa, but more recently the Basic Conditions of Employment Act can fulfil this role) and conflict. Worker participation schemes can help to alleviate this problem and different forms of worker participation schemes are discussed that can increase efficiency of firms.
\end{abstract}

*To whom all correspondence should be addressed.

\section{Introduction}

The 1981 International Labour Organisation's report on worldwide participation in decision-making identifies ethical, socio-political and economic objectives as the three main objectives of participation schemes (Jones \& Maree, 1989: 4). While the first two objectives are important, this paper deals with the last objective and focuses on ways how productivity is advanced by worker participation.

The economic objective of worker participation is to increase the efficiency of the firm. The supporters of participation schemes claim that participation improves the morale, motivation and psychological wellbeing of workers. This increases labour productivity and thus ultimately profits. The paper deals with this process by focussing on the factors that may lead to inefficiency in a firm. The principal-agent problem will be discussed and illustrated with the aid of game theory and specifically the prisoners dilemma. The different forms of worker participation schemes will also receive attention. It will be shown that the contribution of worker participation to productivity should be substantial since it does contribute to the mitigation of the elements of inefficiency in a firm.

\section{The principal-agent problem}

\section{The theory of the principal-agent problem}

In economic theory a principal is a person or party that contractually engages an agent to assist him/her in achieving certain goals. In standard neo-classical theory, no distinction is made between the principal and the agent(s). Where the distinction is made, it is assumed that both parties will strive towards the same goal (Stiglitz, 1987 in Eatwell et al., 1991: 967). The principal-agent problem occurs when one takes into account that the principal (employer or manager) and agent (employee) have diverse needs and are working in a world characterised by asymmetric information.
With asymmetric information the principal has some information that the agent does not have and vice versa. Because of asymmetric information the agent does not know what the needs of the principal are. Thus, even if the agent strives only to fulfil the principal's needs, he would still be unable to maximise the principal's utility. The result is that the agent is left to do the only thing that he can, namely to maximise his own utility. The challenge for the principal is thus to draw up a remuneration scheme for the agent that, when the agent tries to maximise his own utility, the principal's utility will be maximised as well. The diverse needs of the two parties complicate the issue. The agent may, for example, reach a point where longer working hours (which the principal would prefer) no longer increases his utility.

Kotowitz (in Eatwell et al., 1991: 549) defines moral hazard as actions by agents that are detrimental to others due to uncertainty or sub-optimal contracts which prevent agents to bear the full consequences or enjoy the full benefits of their actions. This can be seen as an intensification of the principal-agent problem. This takes place if we allow for what Williamson (1981: 534) calls 'self interest seeking with guile', that is opportunism. This is an employeremployee situation where the agent can shirk, while at the same time still receiving his normal remuneration. Laffont (1989: 180) explains it as follows: 'The agent commits himself morally to pursue an action that is determined jointly with the principal. Then it is the principal's doubt concerning the morality of the agent that creates the problem.' Free riding is a moral hazard situation in a team instead of in a principal-agent situation. That is when a team commits themselves to a common goal and one or more members of the team shirk. The shirkers in the team are referred to as 'free-riders'.

Given the presence of asymmetric information, the worker has discretion as to exactly how much effort he is going to exert. When he exerts less effort than optimal for the 
principal because he is unaware of what the optimal is, and does what is optimal for himself, it is referred to as a principal-agent problem. When he exerts less effort than is optimal for the principal although he knows what the principal expects, it is referred to as moral hazard. In both the principal-agent and moral hazard situations there are asymmetric information and divergent needs. The difference is that opportunistic behaviour is present in the case of moral hazard. The implications of the principal-agent and moral hazard problems for the efficiency of a firm will be illustrated in the next section with the aid of game theory.

\section{Game theory and the principal-agent problem: The prisoners dilemma}

Game theory is 'the study of how interdependent decision makers make choices' (Waldman \& Jensen, 1998: 136). In game theory the total payoff of different categories and the information available to participating parties are of crucial importance. The most basic game is the zero sum game in which the total payoff remains the same over different strategies, since one player's gain is always matched by another player's loss. With non-zero sum games the total payoff varies over different strategies. The game played by the principal and agent is normally a non-zero sum game, since the total payoff within the relationship varies with the effort exerted by both players. The principal's effort takes the form of the wage paid to the agent, while the agent's effort takes the form of work performed. It is assumed that the agent's utility is a positive function of wage received and a negative function of effort performed. The principal's utility, on the other hand, is assumed to be a negative function of the wage paid and a positive function of the effort performed by the agent. Each player's utility is thus a negative function of his own effort and a positive function of the other player's effort.

Table 1: Utility matrix of a principal and an agent

\begin{tabular}{l|l|l|l}
\hline \multicolumn{2}{l|}{} & \multicolumn{2}{c}{ Agent's Effort } \\
\cline { 3 - 4 } \multicolumn{2}{l|}{ Principal's Effort } & High Effort & Low Effort \\
\cline { 2 - 4 } & Low Effort & $\mathrm{A}(100,100)$ & $\mathrm{B}(25,135)$ \\
\hline
\end{tabular}

Table 1 represents a possible utility matrix for a game with the above-mentioned characteristics. The imperfect information associated with the principal agent relationship is taken into account by depicting the game as a simultaneous move game. Note that the combined utility varies between different strategies. If both players exert high effort, they each obtain 100 utils (outcome A), 200 utils being the maximum combined sum of utility. If they both assume that the other party will act in bad faith, they each earn only 75 utils (outcome D). If only one acts in bad faith, the shirker secures 135 utils, leaving the other party with only 25 utils (outcome B or C). In this game the dominant strategy for both players is to exert low effort because it is the best option to follow on the assumption that the other party will exert high effort.
The low effort option generates the biggest payoff for the party 'playing' it for as long as it can be hidden from the other party that one party is 'playing' low effort. In the long run, as information about the effort of the other party becomes available, the inevitable will happen that both exert low effort as the high effort playing party react to the knowledge of his partner playing low effort by also playing low effort. The outcome is clearly inefficient, for the combined utility at outcome D is lower than the utility of any other outcome ${ }^{1}$. Given peoples' inclination to act opportunistically, outcome D will be the result although both can be better off if only they could agree to exert high effort. It is suggested that worker participation can contribute to such an agreement being reached and honoured.

\section{Factors responsible for inefficiency}

The basic form of this game is known as the prisoner's dilemma (Waldman \& Jensen 1998: 139). The application of the prisoner dilemma on the employer-employee situation is the focus of the rest of the paper. In this section the emphasis is on the four elements that need to be mitigated in order to 'solve' the prisoner dilemma, namely asymmetric information, misaligned motives, distrust and conflict. The section concludes with a focus on possible approaches to the problem.

\section{Asymmetric information and unaligned motives}

As was discussed in the previous section it is the simultaneous presence of asymmetric information and divergent motives that gives rise to inefficiency. One way to solve the problem would be to neutralise either asymmetric information or the diverse needs of the two parties involved. The situation will now be discussed where only one of the two elements is present (conceding that it may be a somewhat unrealistic assumption).

Let us first discuss a situation where asymmetric information is absent but we do have divergent motivations. Since the amount of effort exerted by the agent is perfectly known, the outcome will be efficient despite the divergent motives of principals and agents. Although workers want to be lazy (their motivation differs from that of their employers), they cannot be because it will be perfectly known to the principal the moment they are and it is thus irrational to be lazy and the moral hazard problem disappears.

The second situation is one where asymmetric information exists, but motives are aligned. The outcome under these conditions will also be efficient despite the information asymmetries that exist. Although workers can shirk, they

\footnotetext{
${ }^{1}$ Robert Axelrod (1984, cited in Waldman \& Jensen, 1998: 183) has illustrated that in a multi-period game the players may indeed end up at outcome A. However, Axelrod made his findings on the assumption that there was no institution(s) from outside which forced one of the players to play high effort while the other party is not. As will be shown in Section 4.2 such institutions may have been present in South Africa in the past and may be present today. His findings also support the argument that is presented in Section 5.3, namely that co-operation is the superior strategy.
} 
would not because by working hard they are maximising their utility (the motivations of the principal and agent are aligned). Also in this situation the moral hazard problem disappears. It does not matter any longer that the agent is selfish, for his selfishness results in the principal's gain as well.

Thus, an efficient outcome will result if either one of the elements is neutralised. However, the information asymmetry problem can only be neutralised (if it is possible to neutralise) at high cost. Workers will find ways to shirk or undermine their principal in some way as long as they have an incentive to do so. The principal has to settle for some second-best solution by monitoring, threatening or giving agents some additional incentive to supply more effort.

Perfectly aligning the motives of both the principal and the agent are just as difficult. People are different and have diverse needs, especially in a working environment. Thus, while it is not possible to neutralise these factors, their severity can be lessened. The better they are addressed, the more efficient is the outcome.

\section{Distrust (and apartheid)}

In a world of perfect information trust plays no role. However, in the absence of perfect information, due to for example a less than 'instantaneous equilibrating market', the agent has to trust the principal to pay him his proper wage, for he has no other way of establishing the true value (marginal revenue product) of his effort to the principal. Likewise, the principal has to trust the agent to apply his effort to the job to which he has been allocated.

In South Africa the principals were historically white and the agents often black and with racial conflict, many agents did not perceive their principals as trustworthy. In the absence of a well-functioning market and trust, agents assumed that they would not reap the fruits of their efforts. Many agents thus tried to maximise their utility by demanding as high a money wage as possible with the help of the unions and at the same time put in as little effort as possible (outcome B of Table 1). This strategy is not what the principal wants and also decrease the efficiency of the firm. Many principals reacted by lowering their own effort (wage paid to the agents) where and when they could to as low a level as possible. This resulted in the inefficient outcome D. Given the existence of asymmetric information and misaligned motives, the cultivation of trust can contribute to coming closer to efficient outcome A.

If, due to some external factor, either outcome B or C is allowed to persist, then in the case of outcome B the agent has no incentive to create trust and, in the case of outcome $\mathrm{C}$, the principal has no incentive to create trust. Apartheid may be viewed as an external factor that allowed the persistence of outcome $\mathrm{C}$, while the new Basic Conditions of Employment Act may be seen as an external factor allowing the persistence of outcome B (Barker, 1999: 1619). Workers and any person that wants to free ride have a common interest to hold up outcome B as the reality, irrespective of whether it is indeed the reality. Free riders must present them as bona fides while they are free riding or try to distract the attention from their own free riding or try to justify it. In these circumstances propaganda becomes important. In the absence of a market and competition that bring us into contact with the reality of scarcity, it becomes very difficult to distinguish between free riders and productive groups or individuals.

Both external factors (Apartheid and the Employment Act) were and are undermining efficiency. Labour efficiency is sometimes understood as labour being allocated to the production point at which it can contribute in the best way to the marginal product of the firm. However, due to asymmetric information, even if the agent is allocated to the production point where his marginal product will be the highest, he still has the opportunity to decide how he is going to allocate his effort. Within the context of this paper efficiency refers to a situation where the agent is both allocated in that point of production where he can contribute in the best way to the firm's marginal product and that he decides to allocate all his effort to the job to which he has been allocated.

\section{Conflict}

When peoples' needs are in opposition, conflict may result. Conflict between the principal and agent or between different agents or different principals results in a misallocation of labour resources (it directs energy away from the production process) and in this sense is inefficient. Recognising and/or addressing the clash of needs can avoid conflict. If all clashing needs in a particular firm are addressed all that remains to be done is to recognise the needs of the other party. This can be done through some form of communication. However, as asymmetric information is always present, it is impossible to recognise all the needs of the other party. It is thus impossible to neutralise conflict in the firm, because the needs of the other party are usually only recognised after conflict has occurred. Conflict is thus a given and its presence in the firm undeniable and should thus not be assumed that it is on account of moral hazard.

\section{Possible approaches to the problem}

For the manager, the issues that need to be addressed in order to address moral hazard in the firm are in the first place diverse needs and asymmetric information. To the extent that it is not possible to address the first two elements of inefficiency, the cultivation of trust and the management of conflict are essential to contain moral hazard. The presence of any of these four factors will contribute to inefficient labour relations and therefore lead to inefficiencies. This section investigates different ways to try and eliminate these factors and enhance efficiency. In section 5 the characteristics of worker participation schemes will be compared to the principles identified below.

Klitgaard (1995: 17-19) showed that income and performance of an agent should be linked. There should thus be a direct link between productivity and remuneration. In this way motivations are aligned. From the agent's point of view, one can lessen the effect of asymmetric information 
by giving him more insight into the marginal product produced by the firm. From the principal's perspective on the other hand, implementing any scheme that makes the effort of the agent public or easier to monitor lessens asymmetric information. The measurement of performance or output is a very problematic issue in reality, e.g. where output cannot be measured in physical units, and can only be achieved at high costs.

Cromie (1998: Ch 3 and 4) gives a discussion of the cultivation of trust in labour relations and makes the following suggestions on how the problem can be overcome. He stresses that in order to cultivate trust, divergent needs must be acknowledged and the conflict that is a natural outflow from this must be managed. In this process ongoing communication is crucial. Communication allows the development of an understanding of the other party's needs. This should be followed by actions addressing those needs if trust is to be developed effectively. Parties must have the necessary abilities to perform the job to which they have been allocated and be given the opportunity to demonstrate their abilities. All players must be involved and the different parties must act consistently. This last principle for cultivating trust is most likely to be effective if there is some sort of formalisation of the labour relationship. Most writers in the industrial relations literature emphasise the point that conflict is managed by recognising its legitimacy and having a framework in place for its open and systematic resolution.

It is important to keep in mind that the four elements of inefficiency are not independent from one another. Mitigating or cultivating one promotes the others indirectly as well.

\section{Worker participation}

It is not possible to give an all-inclusive account of the various manifestations of participation schemes as it is almost impossible because in each firm a particular participation form develops in a unique way. This is how it is supposed to be, for each firm is unique and implementation problems will always be experienced ${ }^{2}$. A participation scheme should thus be 'tailored' to fit the needs and address the problems of a particular firm. For the purposes of this paper only a conceptual framework and broad description of the different types of schemes are given.

\section{Definition}

There is no universal accepted definition of what worker participation entails. In order not to omit any relevant forms of worker participation, the all-inclusive definition is used here. Worker participation is viewed as all 'social or institutional devices by which subordinate employees, either individually or collectively, become involved in one or more aspects of organisational decision making' (Farnham \& Pimlott 1983, as quoted in Salamon, 1992: 340). From this perspective worker participation had its origin with trade

${ }^{2}$ Read Slabbert (1995: 73-77) for a more detailed discussion of the factors that must be present for implementing worker participation successfully. unions, but includes the entire spectrum of management/employee relationships from simple information-giving by management, through joint consultation, collective bargaining and other institutionalised forms of joint regulation, to workers' control.

\section{A conceptual framework}

Worker participation may take on many forms. It can range from those found within enterprises to social policy participation beyond individual enterprises on, for example, national and sectoral levels. Figure 1 is an illustration showing the different forms of worker participation and how they relate to one another and the firm. It provides the conceptual framework for understanding worker participation schemes.

Within enterprises, participation options range from participation at organisational workstation level (involving direct supervisory employee relationships around daily tasks) to high-level participation (involving elected worker representatives). In the first instance, relations are more task-centred while in the latter instance, relations are more power-centred. Beyond these forms of participation, a wave of financial participation schemes has emerged. They include different forms of profit sharing (like equity share schemes) and gain sharing schemes (Salamon, 1992: 348349; Anstey, 1990: 110-112).

By identifying three key elements distinguishing different forms of employee participation, Salamon (1992: 345-347) creates the conceptual framework illustrated in Figure 1. The first key element is whether the method or extent of participation is direct or indirect. Direct forms are reflected by active individual involvement in decision-making processes, and indirect forms by participation through elected representatives. The second element refers to the level in the organisation at which the participation is taking place - at a high or low level. As was explained in the previous paragraph, low-level participation takes place at the workstation, while the highest level of participation takes place at the board of directors' level. The last element is the scope of participation - whether it is task centred or power centred. Direct, lower-level participation in an organisation tends to be task centred, while higher level, indirect participation tends to be power centred.

In Figure 1, participation within the firm is shown to take five basic forms. They are shopfloor participation, joint consultation, collective bargaining, work councils and boardroom participation. Over time other forms have developed to deal with specialist areas like health and safety, productivity and pension funds, and aspects of restructuring that include training (Anstey, 1990: 4).

Shopfloor participation is the direct, low-level and taskcentred forms of participation. With these forms of participation employees and their principals are involved directly at production or service delivery (Anstey, 1997: 7). It includes information sharing (Bendix, 1996: 552), independent work organisations which were developed to counter the alienation employees experience from their work 
as a result of the fragmentation of the production process (Naude, 1994: 19) and teams like quality circles (Anstey, 1997: 9).

Forms of participation that may be classified as direct and/or indirect forms of participation are gain sharing and profit sharing schemes. With these schemes, representation may be present or absent and these forms of participation can be power-centred and be situated at a high level of the organisation or not. As a result they do not fit into Figure 1. Under both schemes a share of the profits are distributed to workers either in cash or as savings of share ownership. The difference is that in the first instance income is linked to the productivity of the individual worker rather than the profitability of the firm.

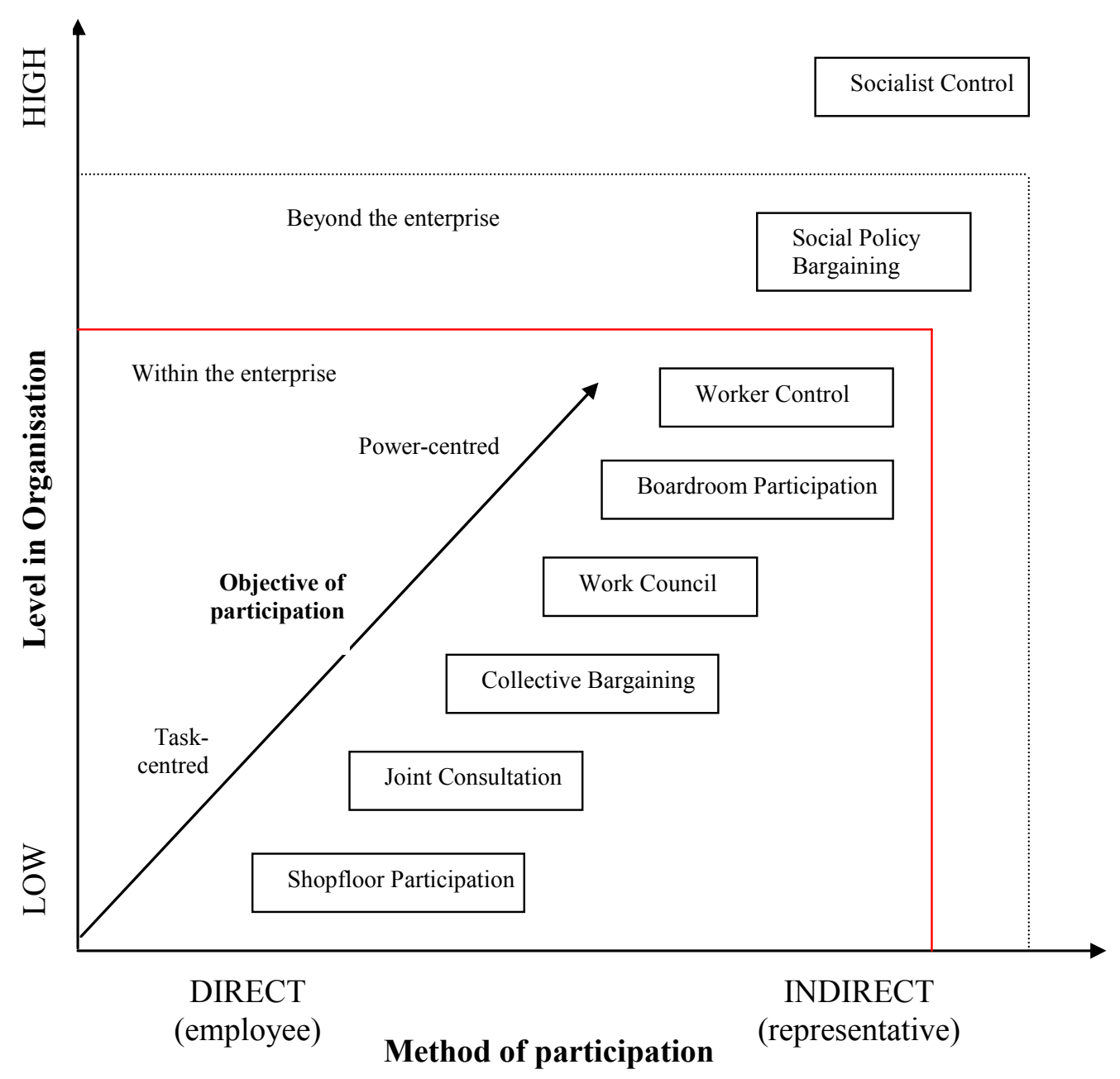

Figure 1: Levels of worker participation

Source: Adapted from Salamon 1992:347.

Indirect forms of participation, which occur through representation, can take place from outside the enterprise through trade unions or it can occur from within the enterprise (Naudè, 1994: 27). Indirect forms of participation include joint consultation, collective bargaining, work councils and boardroom participation and are presented in that order in Figure 1 as an indication of its position within the firm.

Joint consultation entails that employee representatives present their views on certain topics to management in an attempt to influence management's decisions (Naudè, 1994: 23). Collective bargaining differs from normal worker participation on four aspects (Naudè 1994: 39). While worker participation is for all workers, collective bargaining is for union members only. In the participation process workers' influence on decisions is dependent on the equality of representation between labour and capital. This is not the case in collective bargaining as no agreement can be reached without the consent of the union. Participation normally focuses on issues where interests are convergent, but collective bargaining deals with issues of conflict. With participation, co-responsibility must be shared for decisions reached during the participation process, while this does not apply to a collective bargaining agreement.

Work councils in Germany and the Netherlands consist of elected employee representatives empowered to engage management on matters important to them (Anstey, 1997: 7). Although these work councils do not have the right to strike and are legally obliged to assume a co-operative stance their rights to information, consultation and joint 
decision making empower them. With boardroom participation worker directors are elected to the board directly by all employees or appointed by existing union officials (Bennett, 1997: 90). With a second variation there is a split between a 'management' and 'supervisory' board. The system separates management from decision making of the enterprise. The supervisory, which is above the management board have elected employee representatives and are responsible for matters of policy and strategy.

\section{Participation schemes' contribution towards efficiency}

Looking at the above-mentioned characteristics of participation schemes and the requirements of these schemes (as discussed in Section 4.2) to be efficient, it becomes clear that all forms of participation contribute to efficiency in some way. Jones and Maree (1989: 5-6) discuss two South African case studies (Cashbuild and Cape Cabinets) and a summary of studies elsewhere in the world as evidence that participation schemes enhance productivity. However, no single participation form provides all the answers to inefficiency problems. The sole implementation of collective bargaining, or forms of participation aimed at aligning motives, may even aggravate inefficiency instead of contributing to efficiency since no single one participation scheme addresses all the identified elements of inefficiency.

Looking in isolation at collective bargaining, which is presently the most dominant form of worker participation in South Africa, shows that the inefficient situation identified in Section 4.2 can be, at best, kept tolerable. Collective bargaining will not be able to reach the levels of efficiency that can be attained using all the participation schemes in unison. The reason is that the presence of unaligned motives, asymmetric information and trust is to a large extent ignored by collective bargaining.

The remaining forms of worker participation schemes cover all elements of inefficiency. Their weak point is that they neglect the diversity of needs. This is the result of their underlying unitary perspective. The consequence is that, although conflict management may be provided for, the supporters of these forms of participation mostly see conflict as an indication of disloyalty. Worker participation's contribution to efficiency is essential. However, one should keep in mind that although worker participation makes the mitigation of the elements of inefficiency possible, it is not sufficient to ensure an efficient outcome. Additional necessary factors include the aspiration of both labour and management to establish more efficient relations, the presence of a motivated and capable labour relations officer with the support of management (Cromie, 1998:15) and the extent to which socio-political and ethical goals are achieved (Horwitz, 1988: 35-37). However, workers whose position is safeguarded by an act on employment will not necessarily have such aspirations. It is also important to remember that worker participation cannot be more than a strategy initiated by management. When it becomes more than such a strategy it undermines management's mandate to manage.

\section{Conclusion}

Asymmetric information, misalignment of the principal and agent's motives, distrust and conflict create inefficiencies in firms. Worker participation contribute to the mitigation of these elements of inefficiency i.e. enhances the efficiency of the firm and contributes towards employment creation. The efficient firm's approach towards worker participation is neither unitary nor pluralist, but utilises participation schemes on all levels in the firm because it recognises that inefficiencies are always present. Some form of collective bargaining or some other structure for managing conflict is used. By doing so, these firms stand a better chance of being competitive by operating more efficiently.

\section{References}

Anstey, M. 1990. Worker participation, South African: Options and experiences. Kenwyn: Juta.

Anstey, M. 1997. Employee participation and workplace forums. Kenwyn: Juta.

Barker, F.S. 1999. 'On South African labour policies', The South African Journal of Economics, 67(1): 1-33.

Bendix, S. 1996. Industrial relations in South Africa. Third Edition. Kenwyn: Juta.

Bennett, R. 1997. Employee Relations. Second Edition. London: Pitman Publishing.

Cromie, H. 1998. " $n$ Bedryfsielkundige ondersoek na vertroue in arbeidsverhoudinge'. Unpublished Masters Thesis, University of Stellenbosch.

Horwitz, F.M. 1988. 'The propensity for industrial democracy in South Africa: A preliminary assessment of goals', Industrial Relations Journal of South Africa, 8(1): $29-41$.

Jones, G. \& Maree, J. 1989. 'Worker participation and industrial democracy: Two South African case studies', Industrial Relations Journal of South Africa, 9(2): 1-16.

Klitgaard, R. 1995. 'Institutional adjustment and adjusting to institutions'. Washinton, DC: World Bank Discussion Papers.

Kotowitz, Y. 1991. 'Moral hazard'. In Eatwell, J., Milgate, M. \& Newman, P. (Eds.). The new palgrave: A dictionary of economics (Volume 3). London: Macmillan Press, pp. 549551.

Laffont, J.J. 1989. The economics of uncertainty and information. Cambridge, MA: MIT Press.

Naudè, J.P. 1994. 'An industrial relations perspective on the implementation of worker participation in South Africa: Theory and practice.' Unpublished Masters Thesis, University of Stellenbosch. 
Salamon, M. 1992. Industrial relations theory and practice. Second Edition. London: Prentice Hall.

Slabbert, A.M. 1995. 'Demokratisering van die werkplek deur middel van deelnemende bestuur.' Unpublished Masters Thesis, University of Stellenbosch.

Stiglitz, J.E. 1987. 'Principal and agent'. In Eatwell, J., Milgate, M. \& Newman, P. (Eds.). 1991. The new palgrave: A dictionary of economics (Volume 3). London: Macmillan Press, pp. 966-972.

Waldman, D.E. \& Jensen, E.J. 1998. Industrial organization: Theory and practice. New York: AddisonWesley.

Williamson, O.E. 1981 'The economics of organization: The transaction cost approach,' American Journal of Sociology, 87(3): 548-577. 